\title{
Design of ZnO Nanowire Laser Single Mode and Study Its Properties
}

\author{
Ahmed A. Ahmed \\ Physics Dept., Education College \\ University of Mosul, Mosul, Iraq \\ ahmedalnajary30@gmail.com
}

\author{
Rafid A. Abdulla \\ Biophysics Dept., Science College \\ University of Mosul, Mosul, Iraq \\ rafid_albdalali@yahoo.com
}

\section{Received Accepted \\ 05/04/2018 04/07/2018}

\begin{abstract}
Designing of single-mode $\mathrm{ZnO}$ nanowire laser has been achieved. Studying its properties has also been considered. Analysis of single-mode rate equations indicates that the laser has threshold current of $53 \mathrm{~mA}$, the output power of $30 \mathrm{~mW}$ at bias current of $70 \mathrm{~mA}$ and the slope efficiency around $1.77 \mathrm{~mW} / \mathrm{mA}$ for the output power from both mirrors. The critical diameter for nanowire has been calculated and it is found to be $128 \mathrm{~nm}$. The number of nanowire rods through designed area of dimensions $(21 \mu \mathrm{m} \times 21 \mu \mathrm{m})$ has also been calculated. The cavity of nanowire laser is (F-P). The results are compared with some experimental work of $\mathrm{ZnO}$ nanowire lasers and good agreement is found.
\end{abstract}

Keywords: ZnO nanowire laser, Ultraviolet (UV), Threshold current , power output , Fabry-Perot (F-P) micro cavity, waveguide . 


\section{تصميم ودراسة خواص ليزر نانو واير ZnO احادي النمط}

\author{
رافد احمد عبد الله \\ كلية العلوم ، قسم الفيزياء الحياتية \\ جامعة الموصل
}

1234@uomosul.edu.iq

تاريخ القبول

2018/07/04

\section{احمد علي احمد}

كلية التربية للعلوم الصرفة ، قسم الفيزياء

جامعة الموصل

ahmedalnajary30@gmail.com

تاريخ الاستلام

2018/04/05

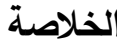

تم في هذا البحث تصميم ليزر نانو واير ZnO يعمل بنمط منفرد وتم دراسة خواصه ايضاً. من تحليل معادلات

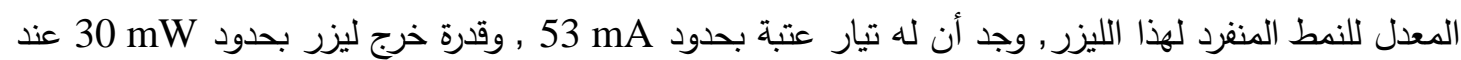

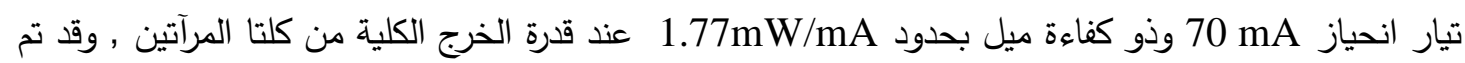

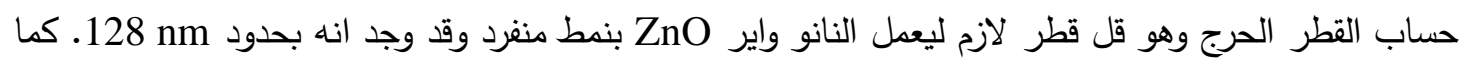
تم حساب عدد أعمدة النانو واير الموجودة خلال مساحة مصممة بأبعاد (F)

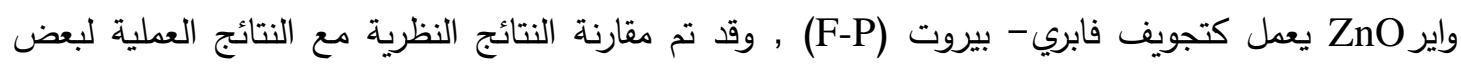
ليزرات نانو واير ZnO ووجد تطابق جيد بينهما.

الكلمات الدالة: ليزر نانو واير ZnO , الاشعة فوق البنفجية (UV) , تيار حد العتبة , القدرة الخارجة، تجويف فابري- بيروت Fabry-Perot (F-P) , دليل الموجة .

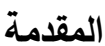

إن ليزر شبه موصل نانو واير يعد كدليل موجة فريد من نوعه الذي ينشأ عن قابليته لإظهار الصفات الفوتونية

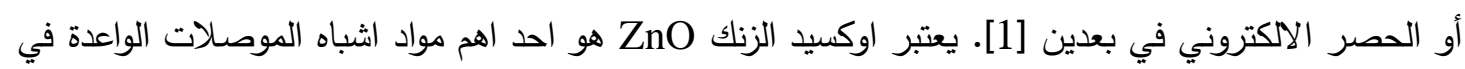

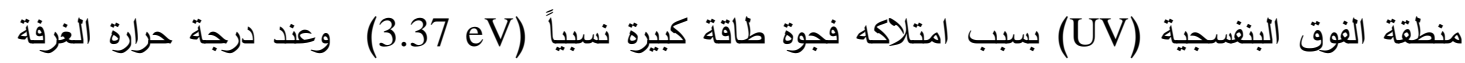
وبطاقة ربط إكسيتون وهي طاقة ربط ( الاككترون- فجوة) بحدود 60 meV [2]. ليزرات اشباه الموصلات التي تعمل في مدى الاشعة فوق البنفجية (UV) هي واسعة الاستعمال في التطبيقات الفوتونية , نقل المعلومات , خزن المعلومات, علوم الحياة , العلاجات الطبية ومعالج الاشارة كما وان هذه التطبيقات في تزايد مستمر

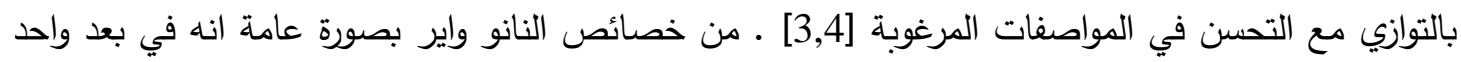

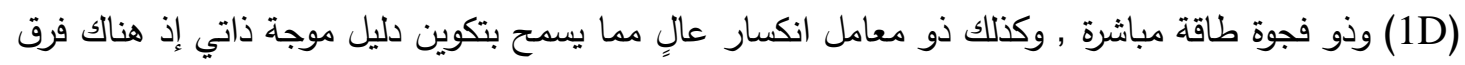


كبير بين معامل انكساره ومعامل انكسار الوسط المحيط به (الهواء عادةً) , وكذلك ذو طيف واسع من الاطوال الموجية التي يمكن الحصول عليهما بسبب الاختلاف في فجوات الطاقة بحسب المادة المستعملة في صنع النانو واير[5]. من المعروف بأن الليزرات التي تعمل بضخ كهربائي تكون افضل اداءً وتفضل في اغلب تطبيقات الليزر عن تلك التي تعمل بضخ ضوئي , وبالنسبة لليزرات اشباه الموصلات فإن اغلب تطبيقاته تتطلب ضـخ

كهربائي لليزر المستعمل. ومن هنا جاءت اهمية تصميم وتصنيع ليزرات نانو واير تعمل بالضخ الكهربائي [6]. هناك كثير من المجاميع البحثية ذكرت طريقة الضخ الضوئي لليزرات نانو واير ZnO [6,7]. لكن على العكس هناك عدد قليل من الابحاث التي تصف [8]. الضخ الكهربائي لليزرات نانو واير • بلورة كبريتيد الكادميوم

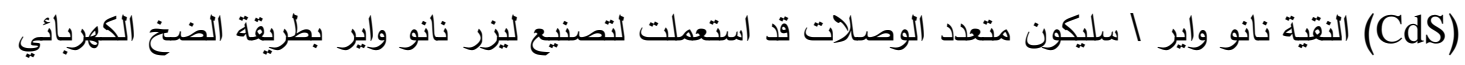

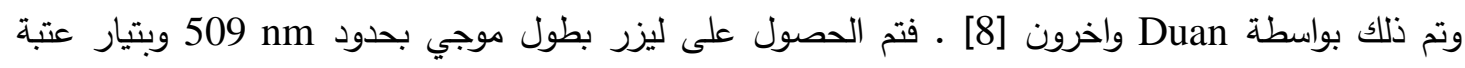
A 200 [8 A

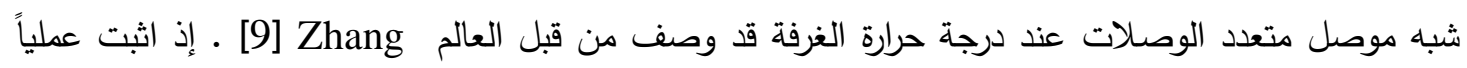

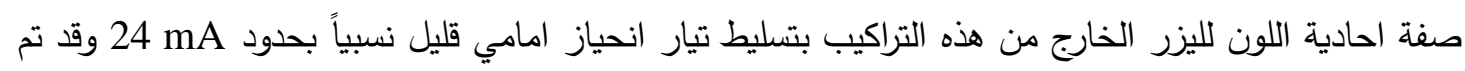

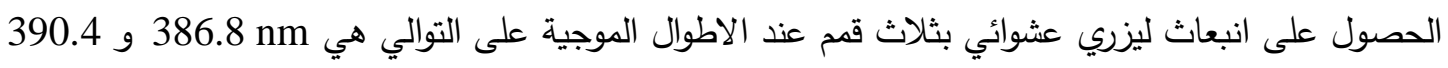

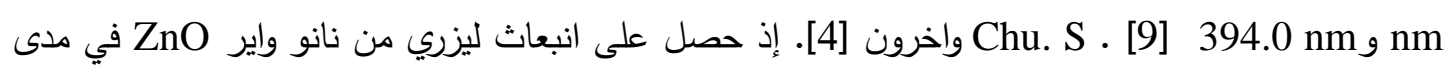
الاشعة فوق البنفجية القرببة وبطول موجي

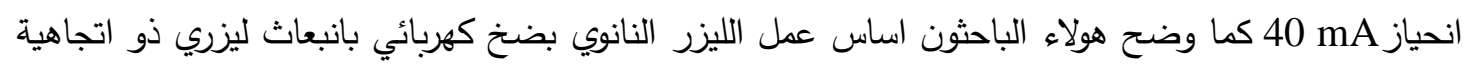

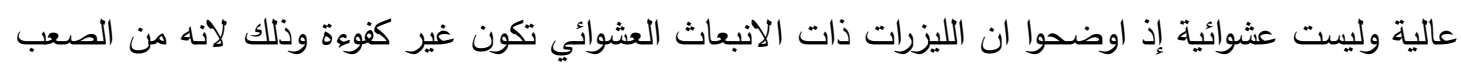

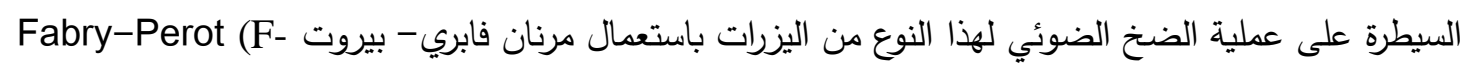

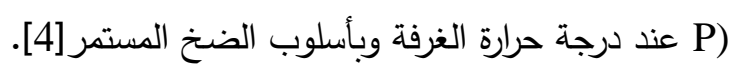

إن نوعية النمط الذي يعمل به الليزرات عامة و ليزرات اشباه الموصلات خاصة مثل ليزر نانو واير ZnO يعد واحداً من اهم خواص الليزر والتي تحدد نوعية تطبيقاته مثلا في الاتصالات الضوئية , المتحسات ومعالجات لئيل الاشارة , لذلك فإن الحصول على ليزر نانو واير يعمل بنمط منفرد , اضافة إلى الضخ الكهربائي وبصيغة

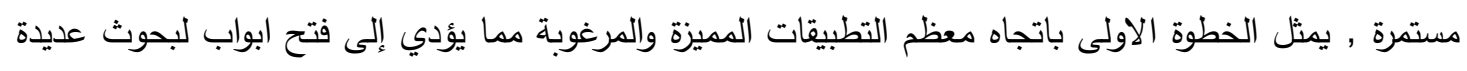
ومتتوعة في مختلف نواحي ومجالات النانو واير ليزر [10].

إن تصغير النبائط الفوتونية ومن ضمنها الليزرات النانوية يعد من الامور المهمة التي قد حظيت بعناية كبيرة

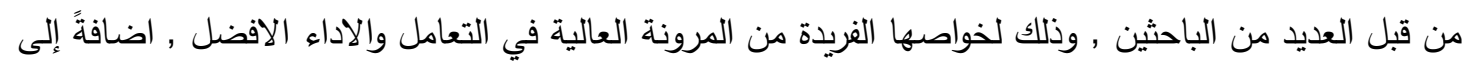
الكثافة العالية في التكامل في الدوائر الالكترونية [10] ـ . إن تصغير الليزرات إلى اقل حد ممكن , في في حدود فئه

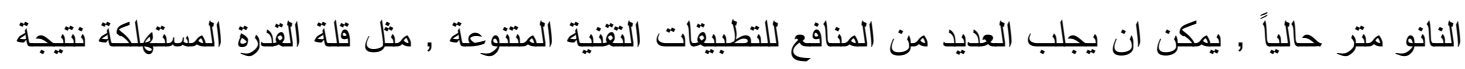

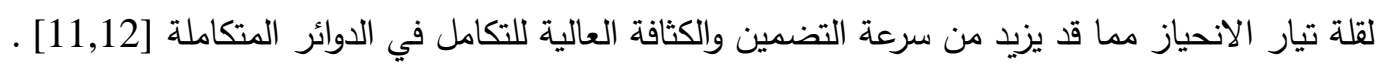
في هذا البحث سيتم تناول كيفية تصميم ليزر نانو واير ZnO يعمل بنمط منفرد وتحديد الشروط اللازمة لذلك ونك من طول وقطر نانو واير مناسب ودراسة خواصه. 


\section{1 - InO تصميم ليزر نانو واير}

ان شكل النانو واير ZnO من حيث المقطع العرضي , الذي هو في الواقع سداسي مضلع , يمكن اعتباره على انه اسطواني الثكل تقريباً، وهذه المقاربة مقبولة ومعتمدة من قبل عدد كبير من الباحثين [1] ـ ان هذه هوفير الليزرات

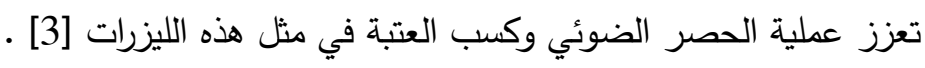

إن تصميم ليزر نانو واير ZnO قيد الدراسة هو يثابه في بعض جوانبه من حيث التركيب لليزر الدقدم من قبل [4] Chu.S

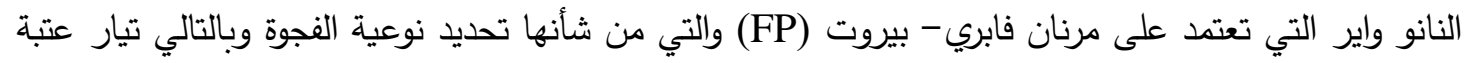

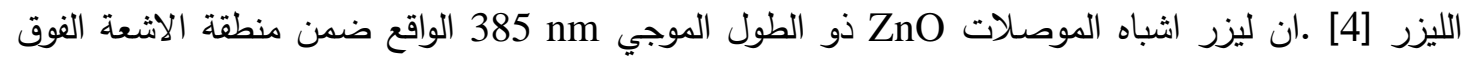
البنفسية UV والذي يعمل بالصيغة المستمرة وبدرجة حرارة الغرفة يكون منتظم ذاتياً وطبيعياً اثناء عملية

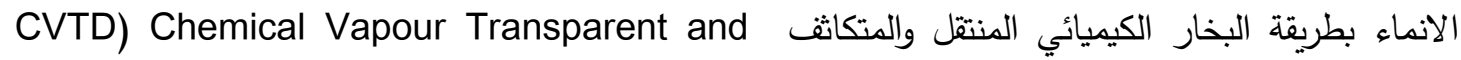
(Deposition ينتج من انماط متثاكهة بسبب نهاتي السلك التي تثبه الى حد ما الثكل الكروي وان هذه الانماط تتناسب

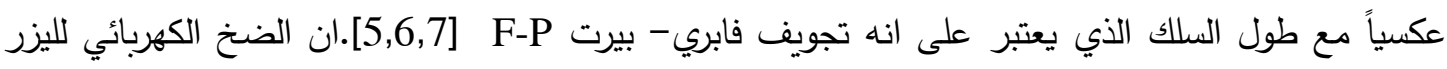

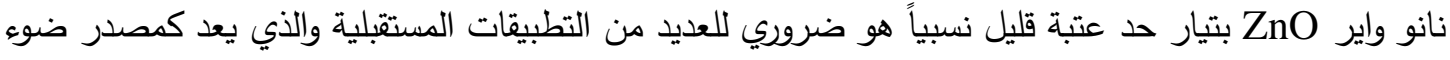
ليزر مثالي مكون من مواد نانوية تحصر الليزر ببعد واحد المصنع وبنفس طريقة الانماء السابقة واثثاء عملية الترسيب ويتكون بذلك تركيب متعدد الوصلات من مركب نوع p-ZnO نانو واير/ طبقة من نوع n-ZnO

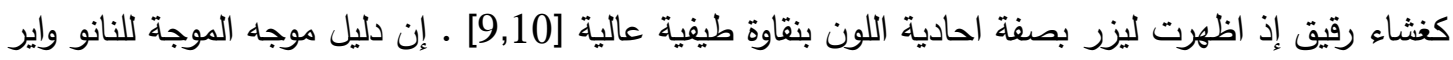

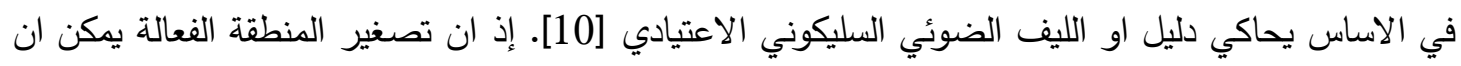

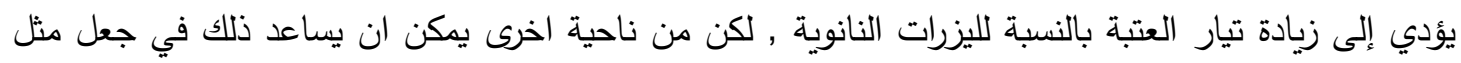

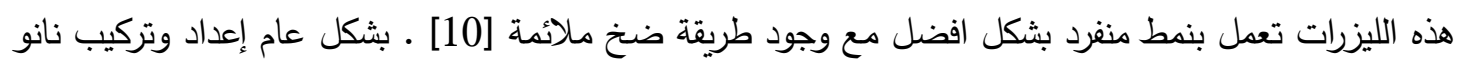

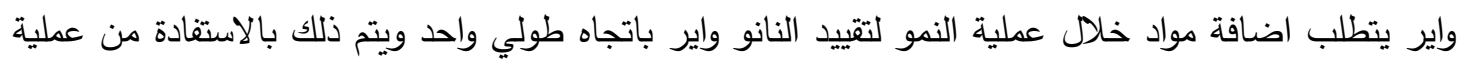
تدعى بطريقة (بخار - السائل- الصلب) VLC وهي انماء بطريقة ترسيب كيميائية تسمى ايضاً بطريقة (اسفل -

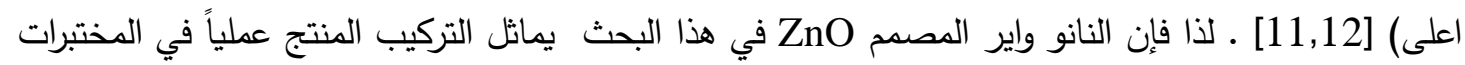
الذي يكون ذو تجانس وانتظام ونقاوة عالية , مما يساعد في تكوين دليل موجة مثالي لتوجيه ضوه الليزر داخله

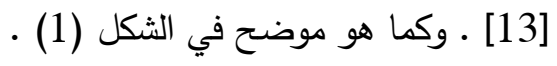

أن الاطياف الانبعاث التي تنتج من نهاية اوجه النانو واير كانت اكثر قوة من الاوجه الجانبية للنانو واير هذه

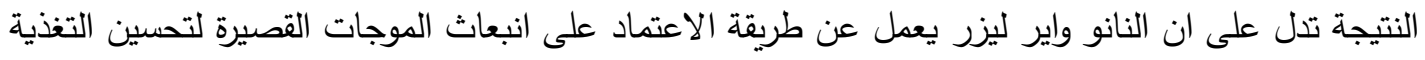
الاسترجاعية في التجويف البصري , ان النانو واير اقل من قطر معين (القطر الحرج ) يكون غير قادر على لى توليد الليزر بسبب ان النانو واير الذي يعمل كدليل موجي غير قادر على حصر الانماط بداخل النانو واير.

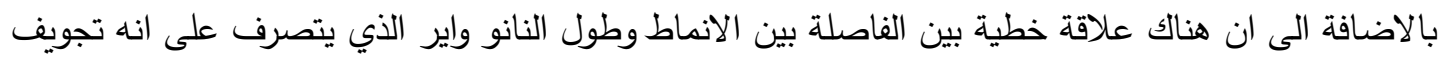

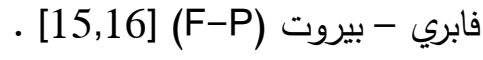


إن شبه موصل نانو واير ZnO هو ذو قلب يمتاز بمعامل انعكاس عالي على النقيض منه الوسط المحيط

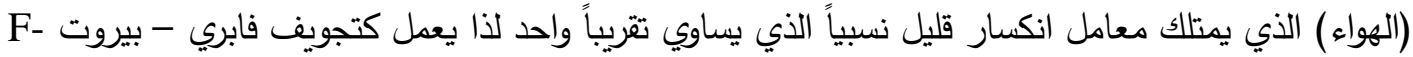

إن منطقة الاتصال العليا للنانو واير هي من نوع (p-type) صممت بطريقة هندسية ومن مواد خاصة بحيث تكون شفافة للضوه بصورة جيدة وبمقاومة كهربائية واطئة لليزر الخارج [4]. وإن طول التجويف (المسافة بين

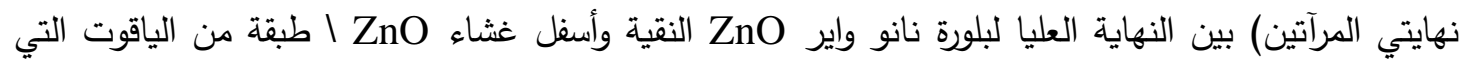
تثكل السطح الفاصل[4]. تجريبياً, ان الارتفاع بين نهايتي الوجهين للنانو واير لا يعد طولاً ضرورياً في تراكيب ليزر نانو واير , لذا فإن

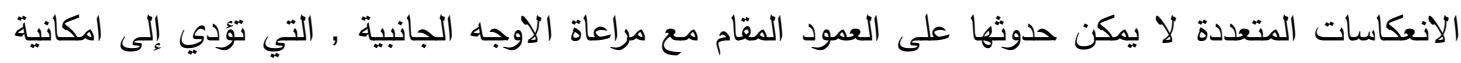
تصميم انواع عديدة من التجاويف (المرنانات) [18] ـ لذلك مثل هذه الظاهرة تمكن هكذا نوع من ليزرات نانو

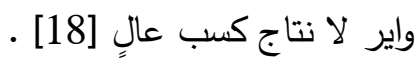

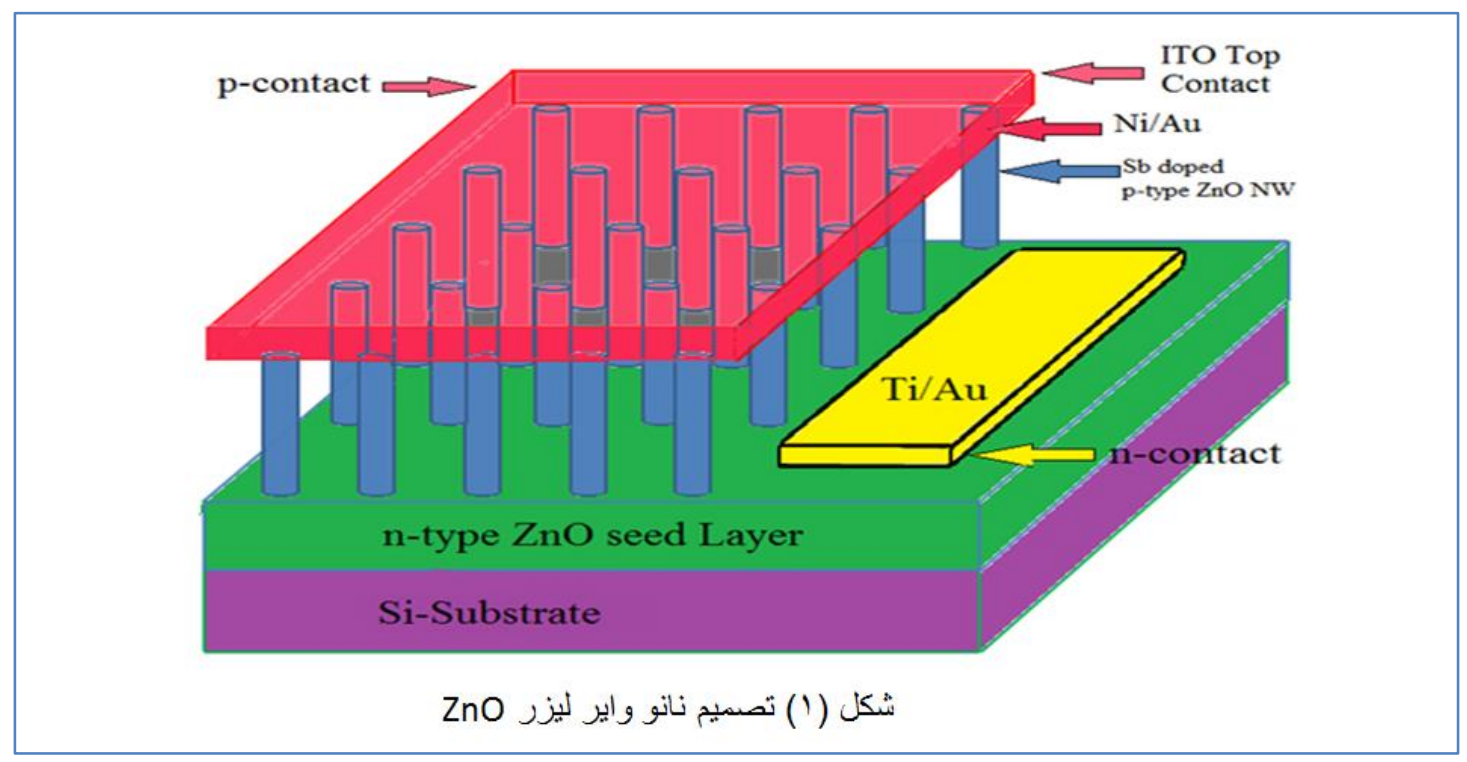

الحسابات الاولية لهذا التصميم أخذت من ارتباطها بالعمل التجريبي [1,4] , وقد تمت الحسابات النظرية الاخرى

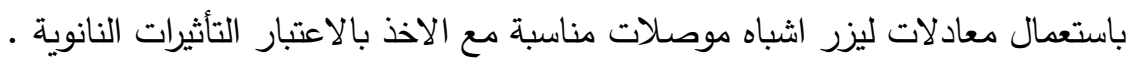
إذ افترضت المساحة المهيئة للتصميم هي (21 بm × 21 (21) وعند تحويل وحدة الطول إلى النانو متر :نحصل على :

$21 \mu \mathrm{m}=21 \times 10^{3} \mathrm{~nm}$ وان عدد النانو واير لكل 21×10³m هي : $\frac{21 \times 10^{3} \mathrm{~nm}}{120 \mathrm{~nm}}=175$

عدد النانو واير على المنطقة الفعالة في بعد واحد بطول 21 سm هي : 
$\frac{175}{3}=58.33$

عدد النانو واير في بعدين أي كثافة النانو واير في المنطقة الفعالة على مساحة التصميم هي :

$\mathrm{N}=58.33 \times 58.33=3402$ nanowires

المسافة بين اثثين من النانو واير المتتاليين في المنطقة الفعالة لليزر هي nm 240 أي ضعف قطر النانو واير. وهذا التركيب يحاكي النانو واير المنتج عملياً [4].

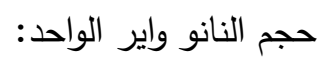

Volume of nanowire $=$ Length of active region $\left(\mathrm{L}_{\mathrm{ar}}\right) \times$ cross sectional area $(\mathrm{A})$

$\mathrm{V}_{\mathrm{n}}=\mathrm{L}_{\mathrm{ac}} \times \mathrm{A}$

$V_{n}=2.60 \times 10^{-14} \mathrm{~cm}^{3}$

الحجم الكلي لجميع النانو واير تم حسابه باستعمال العلاقة الآتية :

The total equivalent volume $=$ volume of one nanowire $\times$ number of nanowire per unite area

$V_{T}=2.60 \times 10^{-14} \mathrm{~cm}^{3} \times 3402=8845 \times 10^{-14} \mathrm{~cm}^{3}$

$$
\begin{aligned}
& \text { حيث كثافة الحاملات عند العتبة [4] هي: N } \\
& \text { إن تركيز الحاملات عند العتبة n يعطى بالعلاقة الأتية : }
\end{aligned}
$$

$\mathrm{n}_{\text {th }}=\mathrm{V}_{\mathrm{T}} \times \mathrm{N}_{\mathrm{th}}$

$\mathrm{n}_{\text {th }}=8845 \times 10^{-14} \mathrm{~cm}^{3} \times 1.1 \times 10^{18} \mathrm{~cm}^{-3}=9.729 \times 10^{7}$

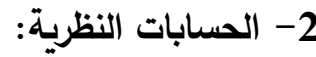

إن انماط دليل الموجة لهذا النوع من النانو واير يمكن معالجتها بمساعدة نظريات دليل الموجة الضوئي

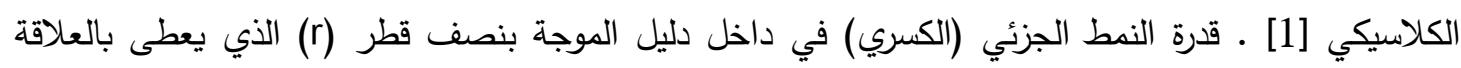

$$
\begin{aligned}
& \eta_{m o}=1-\left[2.405 \exp \left(\frac{1}{V}\right)\right]^{2} V^{-3} \\
& V=k r\left(n^{2}-1\right)^{0.5} \\
& V=(2 \pi r / \lambda)\left(n^{2}-1\right)^{0.5}
\end{aligned}
$$




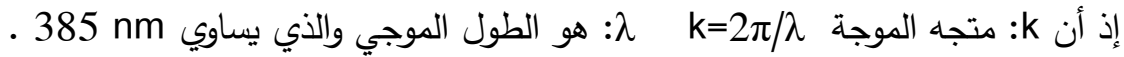

n: هو معامل انكسار قلب النانو واير والذي يساوي 2.5 وعند التعويض في المعادلة عن مدى من الاقطار

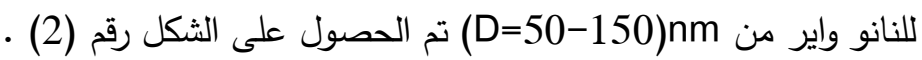

ومن خلال الرسم تم الحصول على عامل الحصر الضوئي D=128 nm وكان ذلك عند القطر

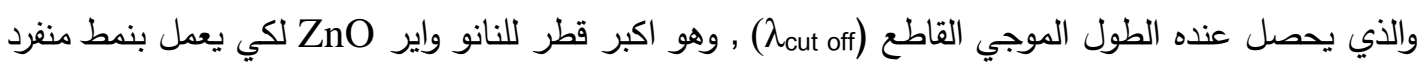
وعند اكبر تلك القيمة يعمل النانو واير ZnO بنمط متعدد والتي هي غير مرغوبة في العديد من التطبيقات وبخاصة في الاتصلات الضوئية .

وبزيادة نصف قطر دليل موجة نانو واير عن القيمة الحرجة لهذا التصميم فأن انماط مستعرضة يمكن ان تتواجد

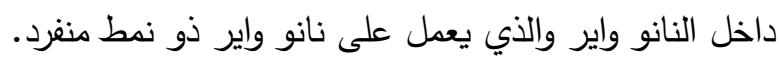

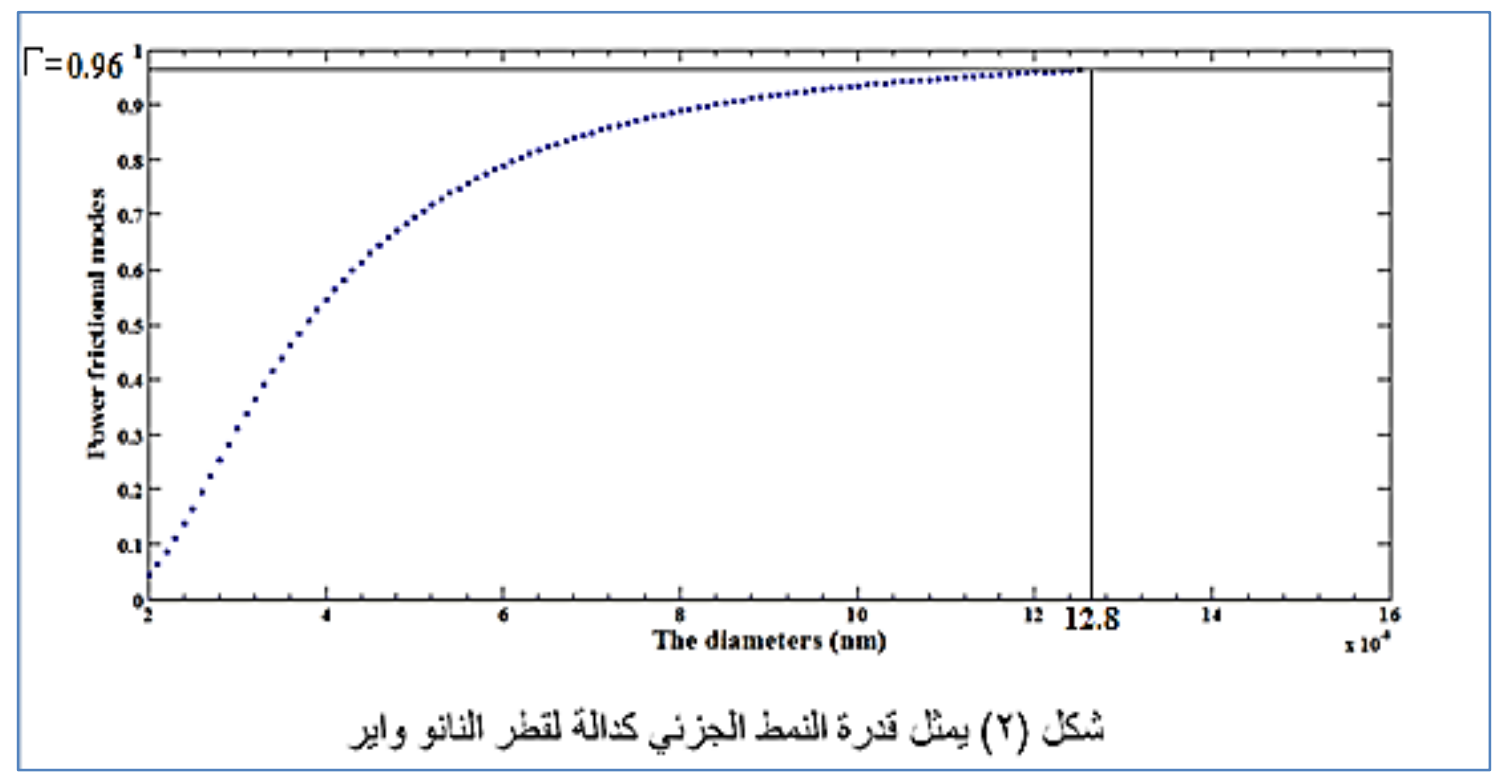

هناك قيم حرجة لنصف قطر دليل موجة نانو واير ليعمل بنمط منفرد , كما هو ملاحظ من التمثيل الرياضي

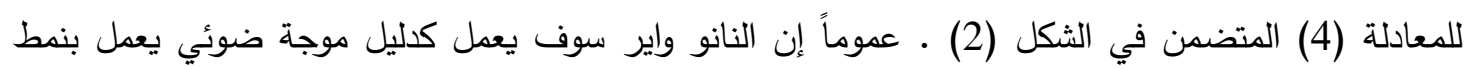
منفرد عندما يتحقق الثرط التالي [20].

$1 \approx\left(\frac{\pi D}{\lambda}\right)\left(n^{2}-\mathrm{n}_{o}^{2}\right)^{0.5}<2.4$

إذ أن 1:هو الحد الأدنى العملي. إن قيمة الحد 2.4 هو بين الواحد و $\left.2.4 \frac{\pi D}{\lambda}\right)\left(n^{2}-{ }^{0.5}\right.$ D: قطر النانو واير , و م هي معاملات انكسار لنانو واير ZnO والوسط المحيط (الهواء) على التوالي • في حالة نانو واير ZnO فان اقل واعظم قطر نحتاجه لغرض الحصول على النمط المنفرد هو بحدود -50) .130) $\mathrm{nm}$ 
إن الضوء المنتج من ليزر نانو واير ZnO هو بالأصل منبعث في موقع إعادة التحام الناقلات (حاملات

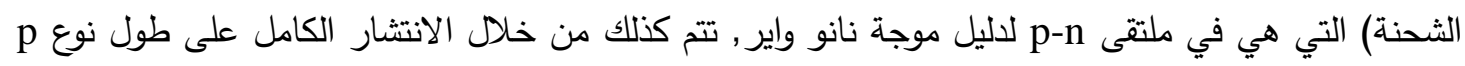
و طول دليل موجة ليزر نانو نانو واير الحقيقي هو نسبي التجويف الليزري هو لا يساوي في الغالب طول فئي

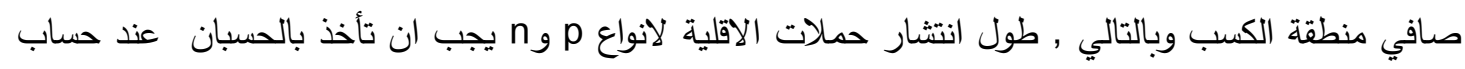

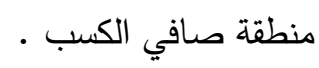
الكسب الثكلي (Gain modal) >g والذي يعرف على انه :

$<g>=\frac{\int E^{*} g E d V_{a}}{\int E^{*} E d V_{a}}$

إذ g: هو الكسب المادي للوسط الفعال (الكسب الثكلي) , هو المجال الكهربائي و V هو حجم المنطقة الفعالة لنانو واير , على فرض ان الكسب هو ثابت في داخل نانو واير (المنطقة الفعالة) وصفر في مكان آخر .

$<g>=\Gamma g=\Gamma_{z} \Gamma_{x y} g$

إذ Г هو عامل الحصر , طول تجويف لنانو واير ZnO هو اكبر بكثير من الطول الموجي الفعال للنمط الموجه هو

$\Gamma_{\mathrm{xy}}=\Gamma=0.96$

ومن الصعوبة بمكان تحديد قيمة معامل الكسب(g) لليزر نانو واير المنفرد لأن الطرائق التقليدية لحسابها تتطلب طول التجويف (L) مع بقاء مساحة المقطع العرضي (A) ثابتة [21]. وفضلا عن ذلك فإن انعكاسات نهاية الوجه ( انعكاسية المرآتين R2 , R ) تكون واطئة , اي أن النمط الطولي الذي يحدث هو بالتزامن مع قمة

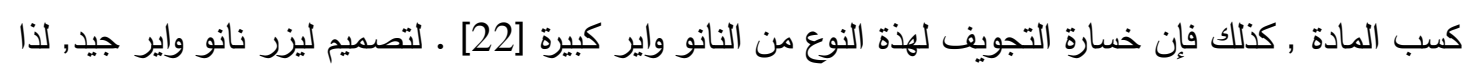
يجب ان تكون طول منطقة الكسب مناسبة مع الاخذ بنظر الاعتبار ان في اشباه الموصلات فان الالكترونات

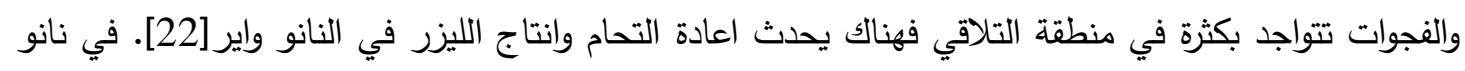

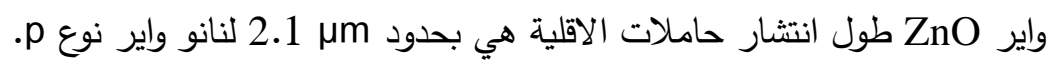

بالاضافة إلى عرض منطقة فراغ الثحنة ـ انه قد وجد بأن طول انتشار حاملات الاقلية تعتمد على درجة الحرارة

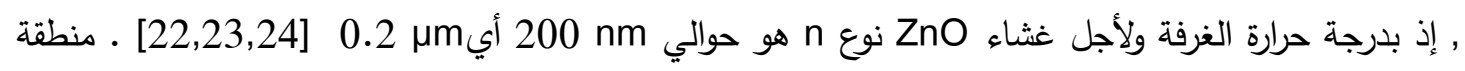

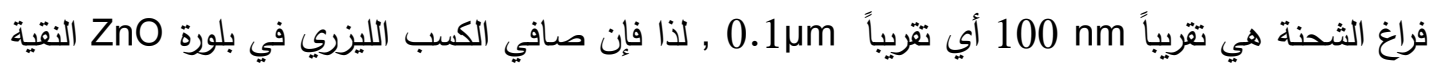
:[4]

$L_{a r}=L_{n}+L_{p}+L_{S}=2 \mu m+0.2 \mu m+0.1 \mu m=2.3 \mu m$

حيث Lي مول طبقة L-type منطقة الكسب . 
ان تذبذب الليزر يحدث عندما يكون الكسب الحاصل في الذهاب وإلاياب يساوي او اكبر من خسارات الذهاب والاياب لكل دورة , في تراكيب اشباه الموصلات النانو واير , الخسارات تتكون من خسارة الانتشار وخسارة المرايا المسيطرة [25] ـ التغذية الاسترجاعية الضوئية يتم توفيرها من قبل المرأتين العاكستين [4] ـ حيث:R

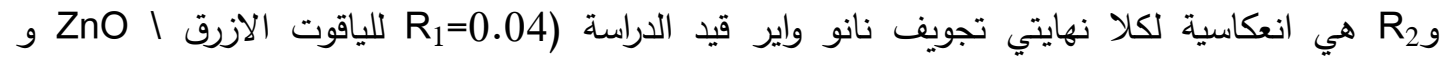

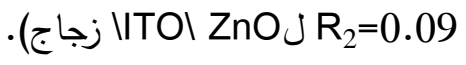
متوسط التباعد بين الأنماط الطولية $\Delta \lambda$ لتجويف F-P يعطى بواسطة [11] . $\Delta \lambda=\frac{\lambda^{2}}{\left[2 L\left(n-\lambda\left(\frac{d n}{d \lambda}\right)\right]\right.}$

L: طول التجويف الكلي والذي يختلف عن طول المنطقة الفعالة Lar في ليزر نانو واير ZnO والذي

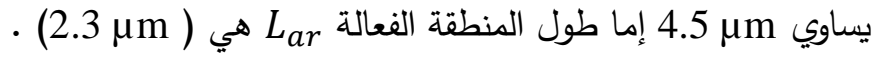
$=1.993 \mathrm{~nm} \Delta \lambda$

ومن المعادلة (9) يتبين ان متوسط التباعد بين الانماط الطولية تقريباُ 2nm ومن المعادلة (10) تبين ان عامل النوعية Q (Quality factor) يساوي:

$$
\mathbf{Q}=\frac{\lambda}{\Delta \lambda}=\frac{v}{\Delta v}
$$
وقد تم حسابه على أنه يساوي: $Q=\frac{385 \times 10^{-9}}{1.993 \times 10^{-9}}$ $Q=193.17$

إن هذه القيمة مقاربة للقيم التي حصل عليها باحثون عديدون عملياً [25,26,27,28] • إن قيمة عامل النوعية (Q) هذه قليلة نسبياً لكنها شائعة ومعروفة بالنسبة لليزرات النانو واير [35 , 28-25] ـ بالرغم من ان هذه القيمة صغيرة الا انه بالامكان الحصول على ليزر بسبب قيمة الكسب العالي لهذه الانواع من الليزرات .

إن انخفاض عامل النوعية لليزر نانو واير ZnO قيد الدراسة والذي يمكن تفسيره على أن النانو واير هو في

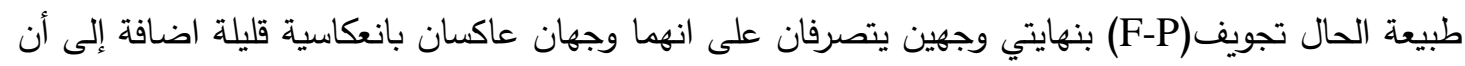

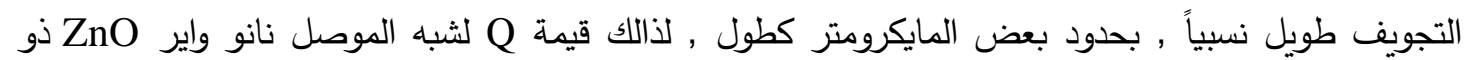
تجويف F-P) يمكن أن يكون بحدود عدة مئات.

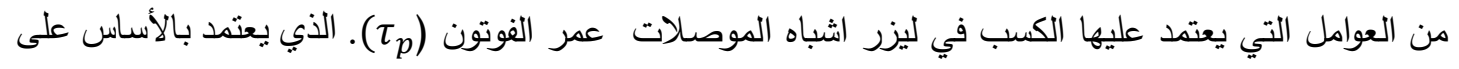

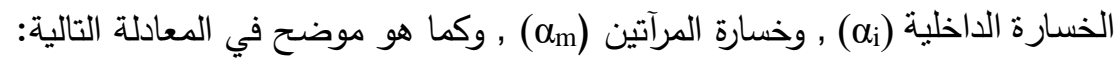

$\frac{1}{\tau_{p}}=\frac{c}{n}\left(\alpha_{i}+\frac{1}{2 L_{a r}} \operatorname{In} \frac{1}{R_{1} R_{2}}\right)$

$\tau_{p}=6.8 \times 10^{-15} s=6.8 \mathrm{f} s$ 
إن الخسارات الكلية (at) في ليزر نانو واير تحسب بالطريقة نفسها التي يتم حسابها في ليزر اشباه الموصلات التقليدي [1]. إن خسارة المرآة هي المهيمنة في ليزر نانو واير بسبب انعكاسيتها القليلة. التشتت يعتمد على الطول الموجي ومعامل الانكسار ويعبر عنه: . [4] $\mathrm{dn} / \mathrm{d} \lambda=-0.015 \mathrm{~nm}^{-1}$

لمركب الليزر قيد الدراسة ـ التشتت في معامل الانكسار في نانو واير ZnO هو ناتج من مجموع التشتت المادي وتثتت دليل الموجة [29] ـ التشتت هو من المفترض كونه ثابت على طول دليل موجة للنانو واير , ZnO يكافئ الخسارة الداخلية , وإن كسب العتبة (gth) يساوي الخسارة الكلية. ان قيمة التشتت واطئة بثدة عند مقارنتها بخسارة المرآة , لذألك يمكن اهمالها وبالنتيجة فإن لئز نانو واير قيد الدراسة , إذ (gth) هو الكسب عند العتبة . إن كسب العتبة لوحدة الطول(gth) يحسب من العلاقة التالية :

$$
\begin{aligned}
& g_{t h}=\alpha_{T}=\alpha_{i}+\alpha_{m} \\
& g_{t h}=\alpha_{i}+\frac{1}{2 L_{a r}} \operatorname{In} \frac{1}{R_{1} R_{2}} \\
& \alpha_{i}=0 \\
& g_{t h}=\alpha_{m}=\frac{1}{2 L_{a r}} \operatorname{In} \frac{1}{R_{1} R_{2}}
\end{aligned}
$$

Lar=2.3 رm : قيد الدراسة LnO طول منطقة الكسب لليزر نانو واير

$g_{t h}=\frac{1}{2 \times 2.3 \times 10^{-4}} \operatorname{In} \frac{1}{0.04 \times 0.09}$

$g_{t h}=1.223 \times 10^{4} \mathrm{~cm}^{-1}$

إن هذه القيمة العالية لوth تقترب من القيمة التقريبية للكسب المقاسة تجريبياً والتي تؤخذ بوحدة من البحوث [4,5] ـ لذا تصمم ليزر نانو واير ZnO ذي النمط المنفرد يجب أن يكون الكسب على الأقل

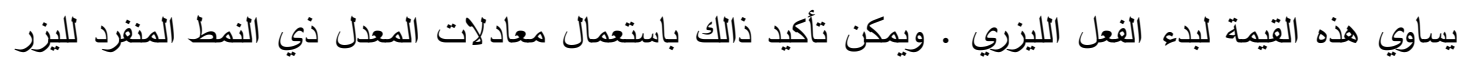
• نانو واير

إن الكسب لوحدة الطول (cmºn $)$ ويمكن أن يُحول إلى كسب العتبة لوحدة الزمن (s) كلآتي [30].

$$
\text { (15) } g_{o}=V_{g} g_{t h}
$$

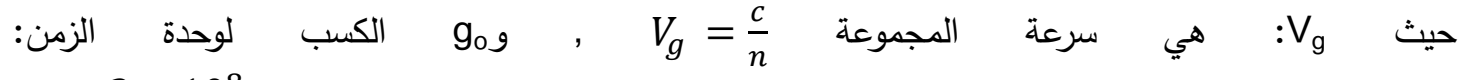
$V_{g}=\frac{3 \times 10^{8}}{2.5}$ 
$V_{g}=1.2 \times 10^{8} \mathrm{~m} / \mathrm{s}$

وبذلك يمكن حساب الكسب لوحدة الزمن بالنسبة للنانو واير ليزرZnO كالآتي :

$g_{o}=1.2 \times 10^{10} \times 1.22 \times 10^{4}$

$g_{o}=1.46 \times 10^{14} s^{-1}$

3- تحليل معادلات المعدل لليزر نانو واير ZnO للنمط المنفرد :

ان معادلات المعدل لليزر نانو واير ذي النمط المنفرد هي تقريباً مشابها لمعادلات المعدل لليزر اشباه الموصلات التقليدية , في الحالات المستقرة ومن خلال معادلات المعدل يمكن إيجاد معدل تغير عدد الفوتونات (S) , وعدد الالكترونات (N) مع الزمن, في ليزرات النمط المنفرد وتحت شرط الضخ الكهربائي وباستعمال

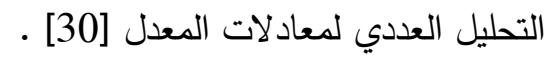

$\frac{d N}{d t}=\frac{I(t)}{q}-\frac{N}{\tau_{n}}-\Gamma g S$

$\frac{d S}{d t}=\beta \frac{N}{\tau_{n}}+\Gamma g S-\frac{S}{\tau_{p}}$

كسب الوسط الفعال يمكن ان يعبر عنه على انه :

$g=\alpha\left(N-N_{o}\right)$

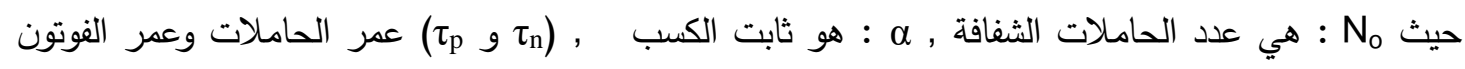
على التوالي • م هو معامل الانبعاث التلقائي , و I(t)/q هو معدل الضخ الكهربائي . وبتطبيق شرط الحالة المستقرة : - المتئ

$\frac{d N}{d t}=\frac{d S}{d t}=0$

وباهمال معامل الانبعاث التلقائي م عند الحالة المستقرة , ومن المعادلة (17) نحصل على :

$\Gamma g \approx \frac{1}{\tau_{p}}$

وبتطبيق شروط الحالة المستقرة , ومن معادلة (16) و(17) و (19) و(20) وبتعويض القيم التي تم حسابها في فقرة الحسابات وتعويض بعض الثوابث نحصل على عدد الفوتونات كدالة لتيار الانحياز : $S=\frac{\left(\frac{I}{q}\right)-\left(\frac{n_{t h}}{\tau_{n}}\right)}{\Gamma g_{o}}$

إذ ح $\tau_{n}=300$ ps كما في [4] ـ عمر الحاملات والتي تساوي إذ nth 
ومن خلال استخدام برنامج ماتلاب (Matlab) تم الحصول على الشكل (3) وايضاً من خلال نفس البرنامج تم

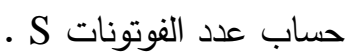

وإن هذه النتيجة لتيار حد العتبة هي قريبة جدأ من النتائج العملية للنانو واير ZnO والمقدمة من قبل [4] . إن العلاقة (21) تمثل عدد الفوتونات كدالة للتيار الكهربائي (تيار الانحياز) , وهذه العلاقة يمكن تمثيلها بالثكل

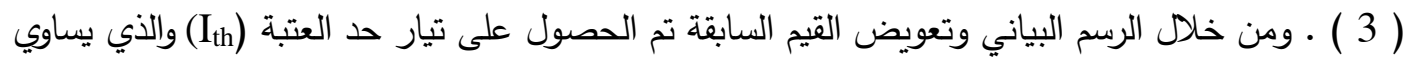
$\mathrm{I}_{\mathrm{th}}=53 \mathrm{~mA}$

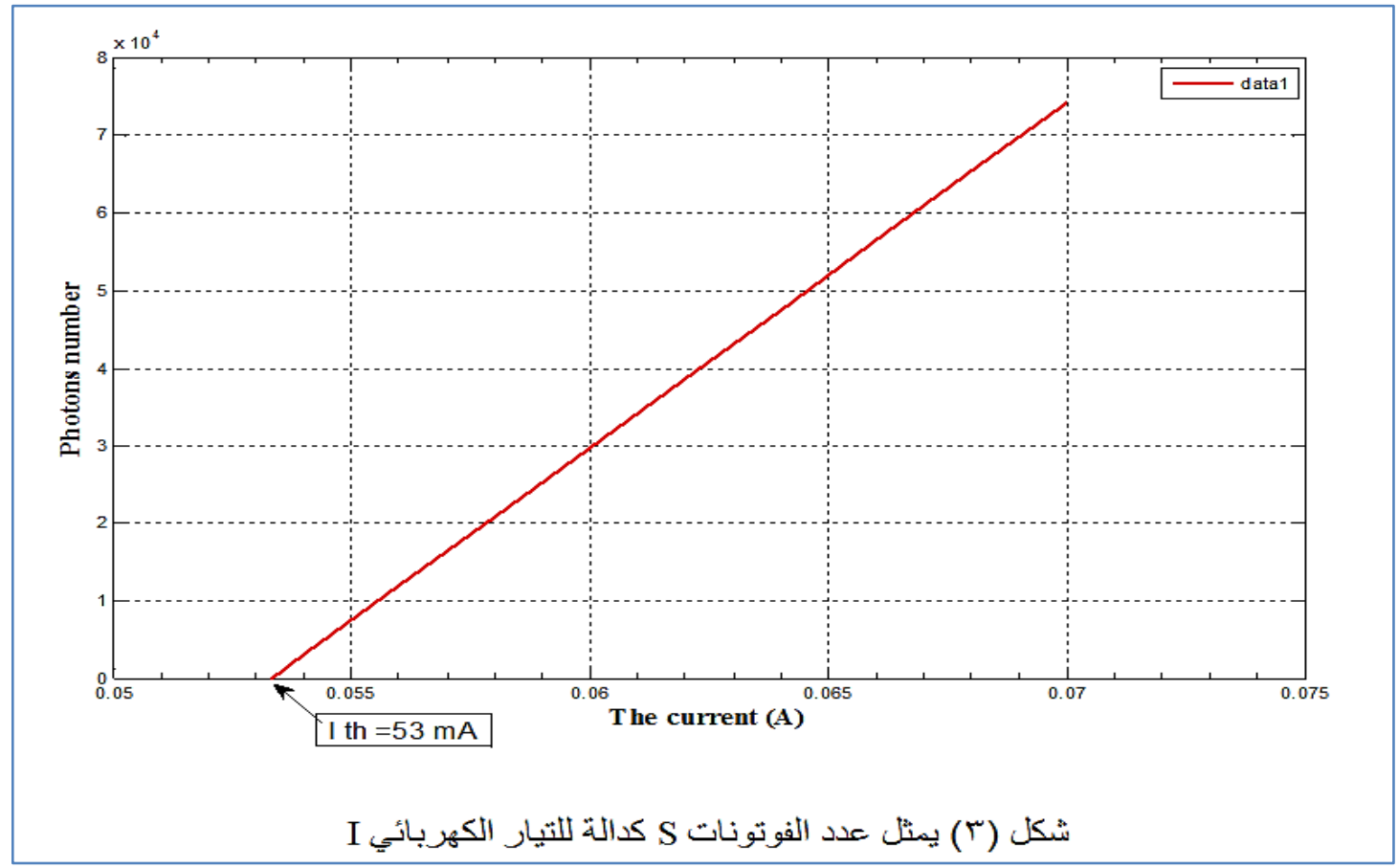

وكما نلاحظ بأن هناك تناسب خطي بين S,I وهذا واضح من العلاقة من حيث بقية المعلمات في العلاقة تبقى

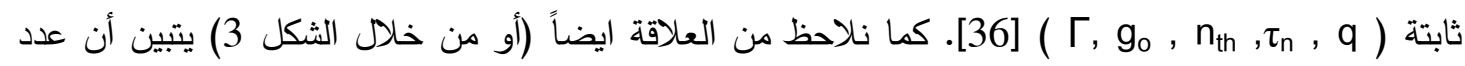
الفوتونات التي تم الحصول عليها هي بحدود بضعة الاف , وهذا العدد يتناسب مع تيار الانحياز القليل بحدود

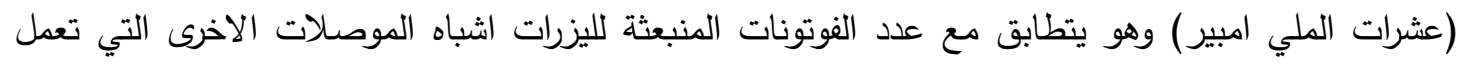

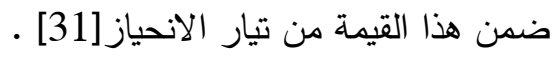

في ليزر نانو واير ZnO هو تقريباً يمتلك خصائص مشابهة لتركيب الليزر قيد الدراسة حيث هذه المعلمات السابقة هي مهم جداً لقياس طيف (القدرة الضوئية وشدة الاضاءة) PL) Photoluminescence) [32,33,34 [ أن الكفاءة الكمية الداخلية Internal Quantum efficiency نانو واير ZnO , التي هي بحدود 0.55 [37] .

إن الكفاءة الكمية الداخلية يمكن حسابها من خلال المعادلة الاتية : $\eta_{i}=\frac{\text { number of photons generated internally per unit second }}{\text { umber of injected electrons in to diodes per unit second }}$

$$
\text { القدرة المنبعثة من ليزر اشباه الموصلات بعد حد العتبة (عند تجاوز حد العتبة لليزر) هي : }
$$




$$
P_{\text {out }}=\eta_{d} \frac{h v}{q}\left(I-I_{t h}\right)
$$

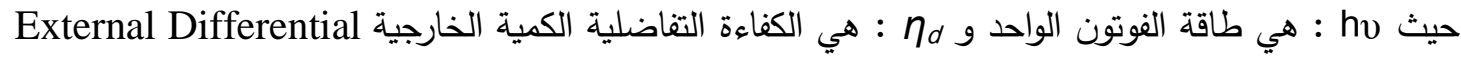
(EDQE) Quantum Efficiency الليزري إلى عدد الالكترونات المحقونة بداخله ـ ويمكن كتابتها على انها :

$$
\eta_{d}=\eta_{i} \frac{\alpha_{m}}{\alpha_{i}+\alpha_{m}}
$$

ومن خلال برنامج (Matlab) تم الحصول على الثكل (4) وايضاً من خلال نفس البرنامج تم حساب القدرة الخارجة من تجويف نانو واير ZnO

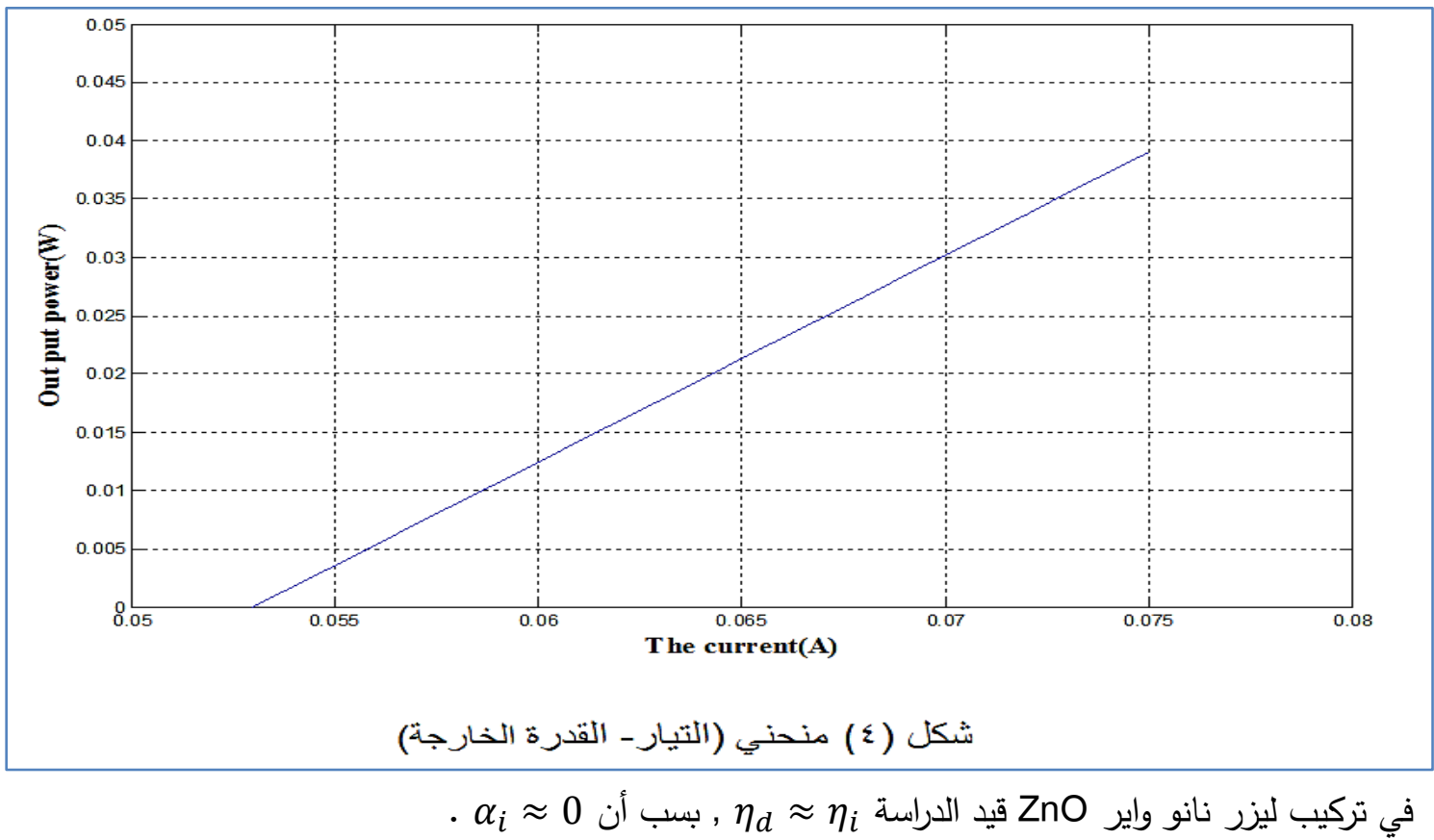

من المعادلة (24) تبين بأن القدرة الخارجة عند تجاوز حد العتبة ستكون دالة خطية للتيار. الكفاءة الداخلية

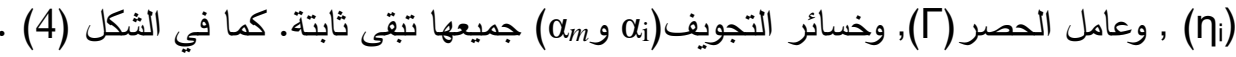
ومن خلال برنامج (Matlab 2015a) حصلنا على الرسم في الثكل (4) كما ويمكن حساب كفاءة الميل (Slope efficiency )

Slope efficiency $=\frac{\Delta \mathrm{P}}{\Delta \mathrm{I}}=1.77$

كما ويمكن حسابها من المعادلة اللآتية [38]:

$$
\begin{aligned}
& \eta_{d}=\frac{\Delta \mathrm{P}}{\Delta \mathrm{I}}\left(\frac{\mathrm{q} \lambda}{\mathrm{hc}}\right) \\
& \frac{\Delta \mathrm{P}}{\Delta \mathrm{I}}=\frac{\eta_{d} \mathrm{hc}}{\mathrm{q} \lambda}
\end{aligned}
$$


إذh: ثابت بلانك والذي يساوي $6.63 \times 10^{-34}$ J.s , وq: شحنة الالكترون والتي تساوي 1.6×10 من C المعادلة (28) يمكن ايضاً حساب كفاءة الميل والتي ايضاً تساوي 1.77

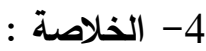

يتبين من خلال هذا البحث ان لليزر نانو واير ZnO تيار حد عتبة قليلاً نسبياً وكفاءة كمية داخلية وميل جيدان

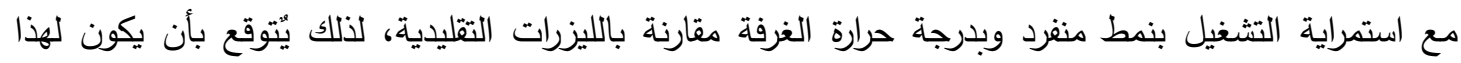
الليزر شأن كبير في المستقبل لامكانية استعماله في مدى واسع من التطبيقات وذلك لصغر حجمه وسه وسهولة

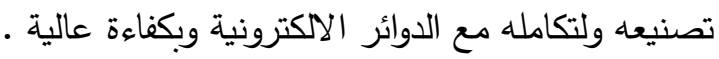

أن المعالم (الباراميترات) المستعملة في البحث مدونة في الجدول رقم (1) : والتي تم حسابها باستعمال معادلات المعدل للنمط المنفرد ومعادلات ليزر اشباه الموصلات .

\begin{tabular}{|c|c|c|}
\hline المعنى & الصبغة & النتيجة \\
\hline 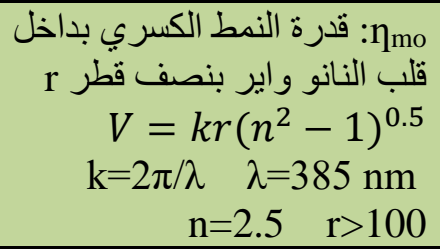 & $\eta_{m o}=1-\left[2.405 \exp \left(\frac{1}{V}\right)\right]^{2} V^{-3}$ & $\Gamma=0.96$ \\
\hline 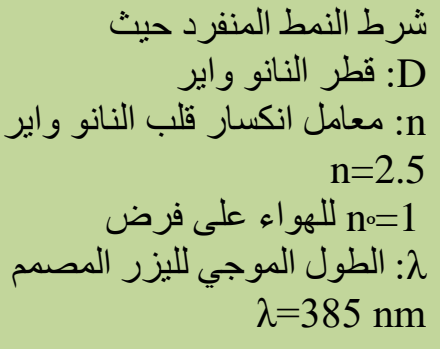 & $1 \approx\left(\frac{\pi D}{\lambda}\right)\left(n^{2}-\mathrm{n}_{o}^{2}\right)^{0.5}<2.4$ & 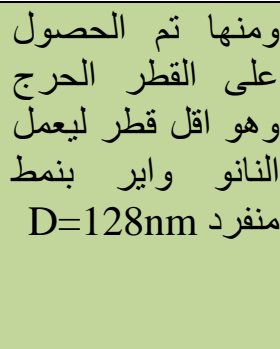 \\
\hline 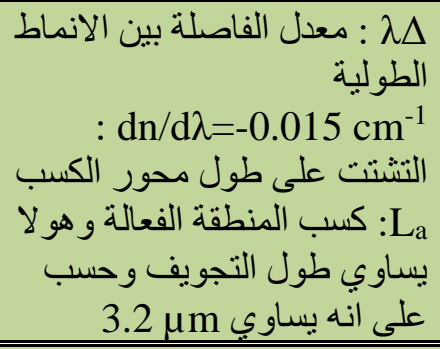 & $=\frac{\lambda^{2}}{\left[2 L\left(n-\lambda\left(\frac{d n}{d \lambda}\right]\right.\right.} \Delta \lambda$ & $=2 \mathrm{~nm} \Delta \lambda$ \\
\hline عامل النو عية لليزر نانو و اير & $\mathrm{Q}==\frac{v}{\Delta v} \frac{\lambda}{\Delta \lambda}$ & $\mathrm{Q}=192$ \\
\hline 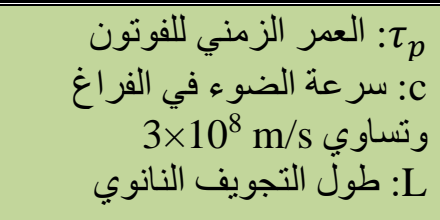 & $\frac{1}{\tau_{p}}=\frac{c}{n}\left(\alpha_{i}+\frac{1}{2 L} \operatorname{In} \frac{1}{R_{1} R_{2}}\right)$ & $\tau_{p}=1.33 p s$ \\
\hline
\end{tabular}


ان بعض الباراميترات (المقاييس) قد تم تبنيها استنادأ إلى مصادر ذات علاقة وطيدة بالبحث

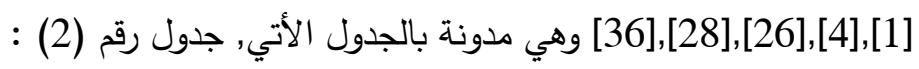

\begin{tabular}{|c|c|}
\hline 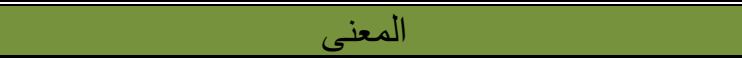 & 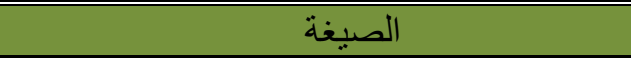 \\
\hline 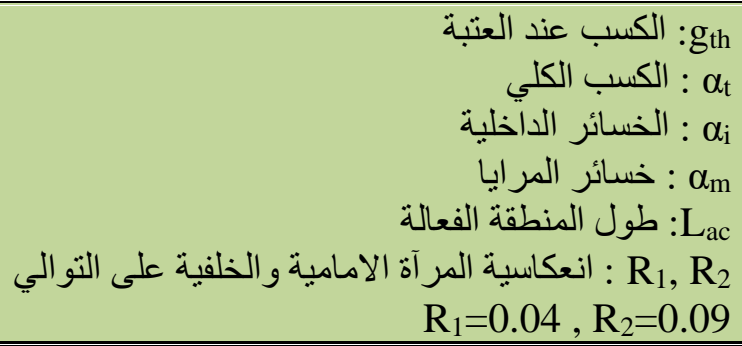 & $\begin{array}{l}g_{t h}=\alpha_{t}=\alpha_{i}+\alpha_{m} \\
g_{t h}=\alpha_{i}+\frac{1}{2 L_{a c}} \operatorname{In} \frac{1}{R_{1} R_{2}} \\
\alpha_{i} \text { تهمل لصغر }\end{array}$ \\
\hline طول المنطقة الفعالة في النانو واير ZnO & $\begin{array}{c}L_{a c}=L_{p}+L_{n}+L_{c} \\
L_{a c}=2.1 \mu m+0.2 \mu m+0.1 \mu m \\
=2.3 \mu \mathrm{m}\end{array}$ \\
\hline عمر حاملات الثحنة & $\tau_{n}=300 \mathrm{ps}$ \\
\hline تركيز الحاملات عند حد العتبة & $N_{t h}=1.1 \times 10^{18} \mathrm{~cm}^{-3}$ \\
\hline الكفاءة الكمبة التفاظلية الداخلية & $\eta_{d}=0.85$ \\
\hline معامل انكسار قلب النانو واير قبد الدر اسة & $n=2.5$ \\
\hline الطول الموجي للنانو و اير قبد الدراسة & $\lambda=385 \mathrm{~nm}$ \\
\hline الدراسةة بين اثثين من النانو واير المتتاليين للنانو واير قيد & $d=240 \mathrm{~nm}$ \\
\hline
\end{tabular}

المصادر:

1. Johnson J. C., Yan, H. Q., Yang, P. D. \& Saykally, R. J. Optical cavity effects in $\mathrm{ZnO}$ nanowire lasers and waveguides. J. Phys. Chem. B 107, 8816-8828 (2003).

2. Okazaki K., Kubo K., Shimogaki T., Nakamura D., Higashihata M., and Okada T. Lasing characteristics of $\mathrm{ZnO}$ nanosheets excited by ultraviolet laser beam. Adv. Mat. Lett., Vol. 2, 354-357 (2011).

3. Sattar Z. A., and Shore K. A. Analysis of the direct modulation response of nanowire lasers. J. Lightwave Technol., Vol. 33, 3028, (2015).

4. Chu S., Wang G., Zhou W., Lin Y., Chernyak L., Zhao J., Kong J., Li L., Ren J. and Liu J. Electrically pumped waveguide lasing from $\mathrm{ZnO}$ nanowire Nature Nanotechnology, Vol. 6, 506-510, (2011).

5. Huang M. H., Mao S., Feick H., Yan H. Q., Wu Y. Y., Kind H., Weber E., Russo R., and Yang P. D. Room-temperature ultraviolet nanowire nanolasers Science, Vol. 292, 1897-1899, (2001).

6. Vugt L. K., Rühle S., and Vanmaekelbergh D. Phase-correlated nanodirectional laser emission from the end facets of a $\mathrm{ZnO}$ nanowire Nano Lett., Vol. 6, 2707-2711, (2006).

7. Zhou H., Wissinger M., Fallert J., Hauschild R., Stelzl F., Klingshirn C., and Kalt H. Uniform-sized $\mathrm{ZnO}$ nanolasers arrays Appl. Phys. Lett., Vol. 91, 181112, (2007). 
8. Duan X. F., Huang Y., Agarwal R., and Lieber C. M. Single-nanowire electrically driven lasers. Nature, Vol. 421, 241-245, (2003).

9. Zhang J. Y., Zhang Q. F., Deng T. S., and Wu J. L. Electrically driven ultraviolet lasing behavior from phosphours-doped $\mathrm{p}-\mathrm{ZnO}$ nanonail array/nSi heterojunction. Appl. Phys. Lett., Vol. 95, 211107, (2009).

10. Yaoguang Ma et al. Semicnductor nanowire lasers. Advances in optics and photonics 5, 216-273 (2013).

11. Lieber C. M. Nanoscal Science and technology:building a big future from small thing. MRS Bull. 28, 486-491, (2003).

12. Lieber C. M. and Wang Z. I. Functional nanowires. MRS Bull, 32, 99-108 (2007).

13. Ma, Yaoguang, and Limin Tong. "Optically pumped semiconductor nanowire lasers." Frontiers of Optoelectronics, Vol. 5, 239-247, (2012).

14. Johnson J. C., Knutsen K. P., Yan H., Law M., Zhang Y., Yang P., and Saykallym R. J. Ultrafast carrier dynamics in single $\mathrm{ZnO}$ nanowire and nanoribbon lasers. Nano Lett., Vol. 4, 197-204, (2004).

15. Couteau C., Larrue A., Wilhelm C., and Soci C. Nanowire lasers. Nanophotonics, Vol. 4, 90-107, (2015).

16. Ma Y., Guo X., Wu X., Dai L., and Tong L. Semiconductor nanowire lasers. Advances in Optics and photonics, Vol. 5, 216-373, (2013).

17. Larrue A., Wilhelm C., Vest G., Combrié S., de Rossi A., and Soci C. Monolithic integration of III-V nanowire with photonic crystal microcavity for vertical light emission. Opt. Express, Vol. 20, 7758, (2012).

18. Johnson J. C., Yan H., Choi H.-J., Knutsen K. P., Petersen P. B., Law M., Yang P., and Saykally R. J. Single nanowire waveguides and lasers. Proc. of SPIE, Vol. 5223, 187-196, (2003).

19. Snyder A. W. and Love D. Optical waveguide theory. Kiuwer, Bostonm (1983).

20. Chen C. -L. Elements of optoelectronics and fiber optics. Chicago, (1966).

21. Johnson J. C., Chol H.-J., Knutsen K. P., Schaller R. D., Yang P., F, and Saykally R. J. Single gallium nitride nanowire lasers. Nature Materials, Vol. 1, 106, (2002). https://www.researchgate.net/publication/10871741.

22. Chena L. and Toweb E. Coupled optoelectronic modeling and simulation of nanowire lasers. Appl. Phys. Lett., Vol. 84, 1067, (2004).

23. Lopatiuk-Tirpak O., Cernyak L., Xiu F. X., Liu J. L., Jang S., Ren F., Pearton S. J., Gartsman K, Feldman Y., Osinsky A., and Chow P. Studies of minority carrier diffusion length increase in p-type $\mathrm{ZnO}: \mathrm{Sb}$. J. Appl. Phys., Vol. 100, 086101, (2006).

24. A. Soudi, P. Dhakal and Y. Gu, "Diameter dependence of the minority carrier diffusion length in individual $\mathrm{ZnO}$ nanowire," Appl. Phys. Lett., Vol. 96, pp. 253115, (2010).

25. Zimmler M. A., Capasso F., Müller S., and Ronning C. Optically pumped nanowire lasers: invited review Semiconductor Science and Technology., Vol. 25, 024001, (2010).

26. Gradecak S., Qian F., Li Y., Park H.-G., and Lieber C. M. GaN nanowire lasers with low lasing threshols. Appl. Phys. Lett., Vol. 87, 173111, (2005).

27. Maslov A. V. and Ning C. Z. Reflection of guided modes in a semiconductor nanowire laser. Appl. Phys. Lett., Vol. 83, 1237, (2003). 
28. Wang M. Q., Huang Y. Z., Chen Q., and Cai Z. P. Analysis of mode quality factors and mode reflectivities for nanowire cavity by FDTD technique. IEEE J. Quantum Electron., Vol. 42, 146-151, (2006).

29. Chang S.-W., Lin T.-R., and Chuang S. L. Theory of plasmonic F-P nanolasers. Opt, Express, Vol. 18, 15039-15053, (2010).

30. Ma R.-M., Oulton R. F., Sorger V. J. and Zhang X. Plassmon lasers: coherent light source at molecular scales. Laser Photonics Rev., Nol. 7, 121, (2013).

31. Abdullah R. A., Khallel E. A. Threshold gain dynamic of blue InGaN laser diode with optical feedback. Optic., 124, 2740-2742 (2013). https://www.researchgate.net/publication/267918178.

32. Zhang Y., Russo R. E. and Mao S. S. Quantum efficiency of ZnO nanowire lasers. Appl. Phys. Lett., 87, 043106 (2003).

33. http:/nanowire,Berkeley.edu/wp-content/uploads/2013/01/207_SI.pdf. http://apl.aip.org/apl/copyright.jsp.

34. Reshchikov M. A., Gu X., Nemeth B., Nause J., and Morkoç H. High quantum efficiency of photoluminescence in $\mathrm{GaN}$ and $\mathrm{ZnO}$. Mater. Res. Soc. Symp. Proc. Vol. 892, pp. 0892-FF23-11.1-11.15, (2006).

https://www.researchgate.net/publication/267918178.

35. Yang Q., Jiang X., Guo X., Chen Y., and Tong L. Hybrid structure laser based on semiconductor nanowires and a silica microfiber knot cavity. Appl. Phys. Lett. 94, 101108-1, (2009).

http://apl.aip.org/apl/copyright.jsp.

36. D. J. Sirbuly, M. Law, H. Yan, and P. Yang," Semiconductor Nanowires for Subwavelength Photonics Integration," J. Phys. Chem. B, Vol. 109,pp. 15190-15213, 2005.

37. Foreman J. V., Everitt H. O., Yang J. and Liu J. Influence of temperature and photoexcitation density on the quantum efficiency of defect emission in ZnO powders. Appl. Phys. Lett. 91, 011902-2, (2007).

https://doi.org/10.1063/1.2753540.

38. Mobarhan K. S., Ph.D. Test and Characterization of Laser Diodes: Determination of Principal Parameters. Appl. Fiber Optics \& Photonics, 14, (2007). www.newport.com. 